\title{
LANDSCAPE URBANIZATION AND FARMLAND REDUCTION FROM 2010 TO 2017 IN SOUTH CHINA
}

\author{
Sarah Hasan ${ }^{1 *}$, Wenzhong Shi ${ }^{1}$, Xiaolin Zhu ${ }^{1}$, Sawaid Abbas ${ }^{1}$ \\ ${ }^{1}$ Department of Land Surveying and Geo-informatics, The Hong Kong Polytechnic University, Hong Kong - \\ $\underline{\text { sarah.hasan@,connect.polyu.hk, (lswzshi, xiaolin.zhu)@polyu.edu.hk, sawaid.abbas@gmail.com }}$
}

Commission III, WG VII/4

KEY WORDS: Land Use Land Cover, Landsat, Support Vector Machine, Urbanization, Guangdong, Hong Kong, and Macao

\begin{abstract}
:
Land use land cover (LULC) of Guangdong, Hong Kong, and Macao (GHKM), south china, has undergone significant changes in the last few decades. This study analyze the spatio-temporal LULC changes and urban expansion during 2010 - 2017 using Landsat TM, ETM+, and OLI. The Landsat images were classified using support vector machine (SVM) into seven classes as forest, grassland, water, fishponds, built-up, bareland, and farmland. Several socioeconomic factors were also obtained to determine their impact on LULC. The result shows that during the studied period, massive economic development and urbanization has increased the built-up area from $8.26 \%\left(16,209.61 \mathrm{~km}^{2}\right)$ to $10.31 \%\left(20241.77 \mathrm{~km}^{2}\right)$ and substantial reduction in both farmland from $37.64 \%$ $\left(73,897.77 \mathrm{~km}^{2}\right)$ to $33.05 \%\left(64932.19 \mathrm{~km}^{2}\right)$ and fishponds from $1.25 \%\left(2451.12 \mathrm{~km}^{2}\right) 0.85 \%\left(1674.71 \mathrm{~km}^{2}\right)$. The most dominant conversion were from farmland to built-up and to forest. Furthermore, forest cover increased to $45.02 \%\left(88384.97 \mathrm{~km}^{2}\right)$ in 2017 from $42.38 \%\left(83215.59 \mathrm{~km}^{2}\right)$ in 2010 as a result of different afforestation scheme and policies in order to make Greener study area. The analysis of socioeconomic factors shows that increase in gross domestic product (GDP), total investment in fixed assets, and industrialization has led to urbanization growth on a large scale and reduction of farmland. Therefore, there is pressing need for sustainable development and protection of farmlands.
\end{abstract}

\section{INTRODUCTION}

Land use land cover changes (LULCC) is the most direct expression of intense anthropogenic activity (Mooney, Duraiappah, \& Larigauderie, 2013). In 1992, the United Nations 'Agenda of the Twenty-First Century' officially stimulated research activities related to land use land cover. In 1995 two main international organization were eastablished named as the "International GeosphereBiosphere Programme (IGBP)" and the "International Human Dimensions Programme (IHDP)". Thus, since 2000, the monitoring and simulation of land use land cover change has become a key focus in the field of land change science (Hasan, Shi, Zhu, \& Abbas, 2019; Liping, Yujun, \& Saeed, 2018; Zhu \& Woodcock, 2014).

Land use land cover changes has a negative influence on the climate, ecosystems, surface radioactive forcing (e.g. increased green house gases and ozone layer deterioration), and biodiversity on both local and global scales. Anthropogenic activities link to many disciplines such as economic development, industrialization, modernization, urban planning, and policies. Over the last few decades, land use land cover changes and developments have resulted in population pressure. To accommodate population pressure, the urban growth pattern is towards the peripheral of rural areas (Araya \& Cabral, 2010) causing conversion of natural and semi-natural resources at an unprecedented rate such as conversion of farmland into built-up land (Wu, Ye, Qi, \& Zhang, 2013). This indicating that demand for natural resources is increasing day by day with the increase in population and urbanization is proceeding at staggering speed. These factors may ominously change landscape structures and it is more prevalent in developing countries of the world such as China (Dou \& Chen, 2017; Hasan et al., 2019; Salih, Ganawa, \& Elmahl, 2017; Zhu \& Woodcock, 2014).

${ }^{*}$ China has undergone a significant land use land cover changes and urbanization since the opening of reform and economic policy in 1978. The unprecedented socioeconomic growth, industrialization, different land use policies, and unplanned urban sprawl have led to widespread land use land cover changes especially near the coastal area such as in the Guangdong, Hong Kong, and Macao (GHKM) (Fan, Weng, \& Wang, 2007; Li, Kuang, Huang, \& Zhang, 2013).

GHKM is one of the richest regions in China with total population 9164.90 (10,000 persons) in 2017 which contributes $14 \%$ of the country gross domestic product

\footnotetext{
* Corresponding author
} 
(GDP). These areas were once rich in land resources and were a major source of commercial grain production before 1978. After the opening of economic reform in 1978, the intensive urbanization combined with land use land cover changes have led to the exploitation of natural resources such as depletion of farmland, fishponds, and biodiversity (Hasan et al., 2019; Jiang \& Wu, 2015; Wenhua, 2004). Therefore, to understand the impact of land use land cover changes because of intense socioeconomic activities and to promote sustainable development the objective of this research is as follows. To examine the spatio-temporal Land use land cover changes from 2010 to 2017 using Landsat data and analyze the driving factors behind the change.

\section{MATERIALS AND METHODS}

\subsection{STUDY AREA}

GHKM is located on the sounthern most part of China (Figure 1). It total covers an area of approximately 196,342 $\mathrm{km}^{2}$. The area consists of 23 cities, divided into four groups in accordance with their geographical location. This includes 11 cities in the Pearl River Delta (PRD), five cities in mountainous regions, four cities on the eastern side, and three cities on the western side. Its annual average temperature is $22^{\circ} \mathrm{C}$ and annual average rainfall is 1500 to $2000 \mathrm{~mm}$. It shares boundary with Fujian province in the east, Jiangxi and Hunan provinces in the north, Guangxi in the west, and the South China Sea in the south. Its topography includes rivers, mounatins, plains, and plateaus (Hasan et al., 2019; Shobairi \& Li, 2016).

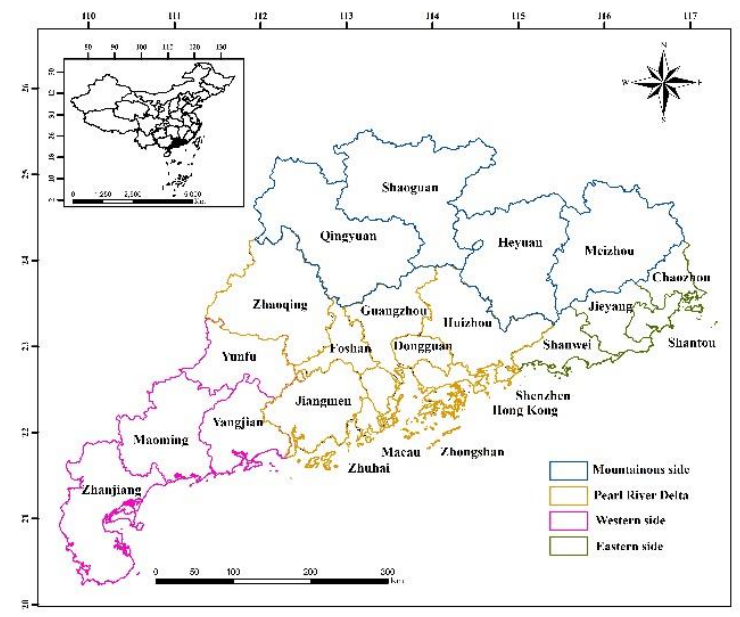

Figure 1. The geographical location of the study area

\subsection{DATA ACQUISITION}

Atmospherically corrected Landsat (Thematic Mapper (TM), Enhanced Thematic Mapper (ETM+), and Operational Land Imager (OLI)) satellite images with 30m spatial resolution from 2010 to 2017 were collected ("USGS Earth Explorer," n.d.). For the corresponding year, Guangdong, Hong Kong, and Macao was cover in Landsat 15 tiles. The dry season (winter) is considered the best period to study land use land cover changes, due to minimal cloud cover and a better capacity to differentiate between grasses and evergreen forest (Hasan et al., 2019). Vector data i.e. Guangdong, Hong Kong, and Macao administrative boundary was used to clip the study area. Socioeconomic data such as population and GDP extracted from Guangdong, Hong Kong, and Macao statistical years book 2010-2017 (Xiaowei, Xiangxin, \& Jianfu, 2017). WGS1984-UTM-Zone-49N projection system was used.

\subsection{CLASSIFICATION OF LAND USE LAND COVER}

A supervised support vector machine (SVM) classification was used to classify the images (Mountrakis, Im, \& Ogole, 2011). SVM has the flexible supervised classifier options with high accuracy when classifying the multispectral data as compared to other supervised classification methods (such as decision tree, maximum likelihood classifier (MLC) and artificial neural network (ANN)) (Gidudu, Hulley, \& Marwala, 2007). Artificial Neural Network has been related with the problems of over fitting and local minima (Candade \& Dixon, 2004), whereas MLC requires large training area (Bahari, Ahmad, \& Aboobaider, 2014) and unable to resolve the interclass confusion. These limitations are overcome by SVM, which does not depend upon any assumptions for the distributions of class data (Mountrakis et al., 2011). SVM is an advanced machine learning statistical algorithm that separates the classes on the basis of optimal decision called hyperplane surface (Mountrakis et al., 2011; Ustuner, Sanli, \& Dixon, 2015). The data point closest to the hyperplane known as support vectors (Rimal et al., 2018). The complexity of resulting classifier represented by several support vectors instead of the dimensionality of the changed space. Thus, the classification based on SVM has been known to strike the right balance between accuracy achieved through a given finite amount of training patterns and the ability to generalize to unseen data. It classify the data both linear and non-linear. For non-linear data, kernel function (linear, radial bias function, sigmoid, and polynomial) is used (Candade \& Dixon, 2004; Mountrakis et al., 2011).

In this study, SVM, a radial bias function (RBF) was used as a kernel function as this kernel yielded higher performance with respect to convergence speed, robustness, and fewer parameter values to predefine. The cost parameter (C) tells the SVM optimization how much we want to avoid misclassifying each training example. For large values of $C$, the optimization will choose a smaller-margin hyperplane, whereas a very small value of $C$ will cause the optimizer to look for a larger margin separating the hyperplane. The gamma parameter defines the influence of a single training example. With a low gamma value, points far away from a plausible separation line are considered in the calculation for the separation line. On the other hand, a high gamma value considers the points close to the separable line. Using ENVI 5.1, Landsat images were classified into forest, grasses, water, fishponds, built-up, bareland, and farmland with the help of some auxiliary google earth higher spatial resolution imagery. The auxiliary data used to select regions of interest (ROIs) as training pixels for each class in the SVM and validate the classification results. The accuracy of the 
classified maps was assessed by means of the producer's accuracy, user's accuracy, and kappa statistics derived from the confusion matrix (Lillesand, Kiefer, \& Chipman, 2008).

\subsection{CHANGE DETECTION AND ANNUAL RATE OF CHANGE}

By post classification comparison of classified maps, temporal changes in the spatial extent of land use land cover classes were determined (Abbas, Nichol, \& Wong, 2018; Hasan et al., 2019). In order to summarize the transition and for further analyses gain (G) (Eq. (1)), loss (L) (Eq. (2)), annual net change (ANc) (Eq. (3)), swap (S) (Eq. (4)), total change (TC) (Eq. (5)), and annual rate of change (R) (Eq. (6)) were calculated.

$$
\begin{aligned}
& G_{j}=P_{+j}-P_{j j} \\
& L_{j}=P_{j+}-P_{j j} \\
& A N c_{j}=\left|P_{+j}-P_{j+}\right| \\
& S_{i}=2 \min \left(P_{j+}-P_{j j} ; P_{+j}-P_{j j}\right) \\
& (T c)_{j}=\left(P_{j+}-P_{j j}\right)+\left(P_{+j}-P_{j j}\right) \\
& R=\left(\frac{1}{T_{2}-T_{1}}\right) \times\left(\ln \frac{A_{2}}{A_{1}}\right) \times 100
\end{aligned}
$$

Where, $\mathrm{P}_{+j}$ represents the landscape proportion of class $j$ in time $2, \mathrm{P}_{j+}$ represents the landscape proportion in class $j$ in time 1 , and $P_{j j}$ represents the persistency of class $j$. Gain $(\mathrm{G})$ is defined as the percentage of landscape structural class in the time 2 after subtracting its proportion from the time 1 landscape. Loss (L) defined as the difference between the percentage of a class of time 1 landscape and its persistent proportion after the period of transition. Absolute Net Change (ANc) defined as the absolute difference of class landscape amount in the time 1 and time 2 landscape. Swap (S) represents the amount of a loss of class at one location and the same amount is added to a different class in the landscape. The total change (Tc) characterize the overall change, calculated by adding gain and loss (Abbas et al., 2018; Hasan et al., 2019; Pontius, Shusas, \& McEachern, 2004).

\section{RESULTS AND DISCUSSION}

The overall accuracy of classified map is $91 \%$ and kappa 0.88. Figure 2 a map and Figure 3 the general trend of land use land cover revealing that land use land cover of Guangdong, Hong Kong, and Macao has changed during 2010 - 2017. Land use type, especially in the Pearl River Delta region, has become one of the most prosperous economic regions in China. The economic reform policies, socioeconomic development, and unprecedented urbanization have changed the Guangdong, Hong, and Macao socially and economically, resulting in land use land cover changes. The most dominant conversion were farmland to built-up and to forest cover. During the studied period, the area of farmland has significantly decreased from $37.64 \%\left(73,897.77 \mathrm{~km}^{2}\right)$ in 2010 to $33.07 \%\left(64,932.38 \mathrm{~km}^{2}\right)$ in 2017 with a net loss $20.64 \%$. The decrease in farmland accounted for urban expansion and forest growth. The buildup area increased from $8.26 \%\left(16,209.61 \mathrm{~km}^{2}\right)$ to $10.31 \%$ $\left(20,643.28 \mathrm{~km}^{2}\right)$ during $2010-2017$ with a net gain of $2.05 \%$ and the annual rate of change $3.17 \%$, during 2010 2017 (Figure 4). The continuous expansion of built-up area from an area of scattered downtown to megacities is due to economic growth and the increasing population. Furthermore, the area of fishponds has decrease from $1.25 \%$ $\left(2451.12 \mathrm{~km}^{2}\right)$ to $0.85 \%\left(1674.61 \mathrm{~km}^{2}\right)$ with a net loss $0.85 \%$ during the studied period. As a result of different afforestation scheme and to make Guangdong, Hong, and Macao greener the forest cover increased from $42.38 \%$ $\left(83215.59 \mathrm{~km}^{2}\right)$ in 2010 to $45.02 \%\left(88,384.19 \mathrm{~km}^{2}\right)$ in 2017 with annual rate of growth $0.86 \%$ and net gain $3.42 \%$.

Developments in science and technology in terms of economic development have promoted urbanization. New built-up areas were mainly concentrated in the center (PRD) and on the eastern side of the study area because of their geographical location. For instance, areas of low elevation wer considered suitable for urban projects and development. The geography of each area resulted in the expansion of urban areas at decreasing rates. In these two regions, farmland and fishponds were the primary contributors to new built-up areas. By comparing the PRD urbanized area with other densely urbanized areas of the world such as the UK $(7.5 \%$ built-up area), the Netherlands $(11.5 \%)$, and Belgium (20\%), the PRD can be described as the most rapidly urbanized region, with built-up areas rising to $10.31 \%$ over the entire study period (Du, Shi, \& Van Rompaey, 2014).

The conversion of farmland to another land use type was eventually restrained by additional and different land policies and legislation. The most influential of these were the "Land Administration Law (LAL)", the "Basic Farmland Protection Regulation (BFPR)", and the "Returning Farmland to Forest Program (RFFP)". These programs aimed (1) to control the expansion of urban areas, and (2) to protect farmland and its conversion. The basic hypotheses of the above policies were rejected due to high investment and the implementation of different development policies that led to a significant occupation of land for construction activities. The result was a constant increase in urban and rural area settlements at the cost of a large reduction of the proportion of farmland and a widening of the urban-rural gap. Thus, urbanization was given priority over the protection of farmland in the current stage of economic development 

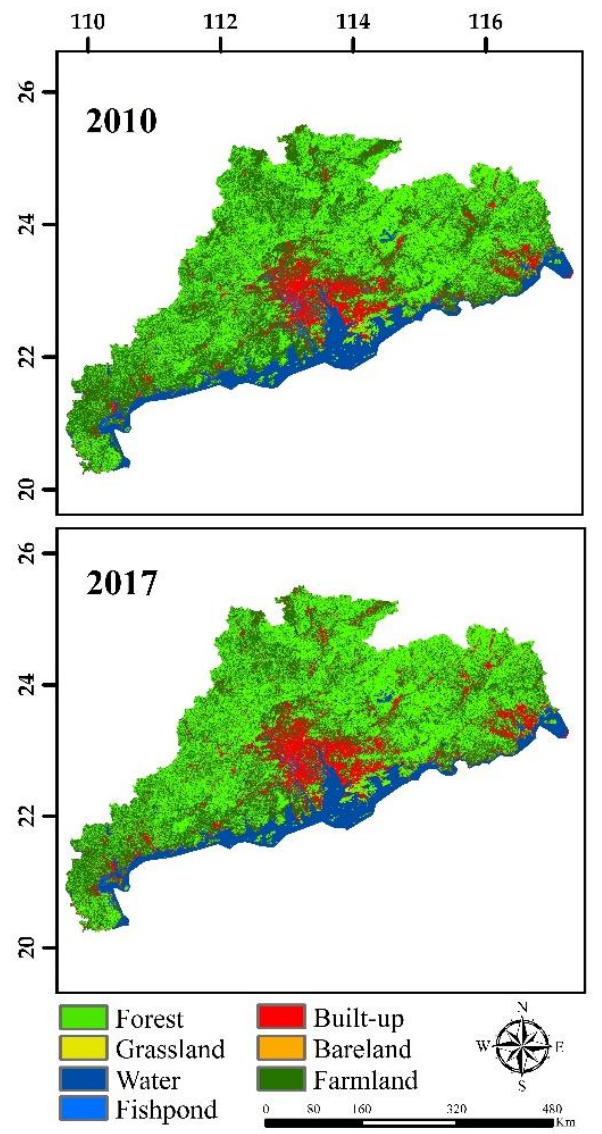

Figure 2. Guangdong, Hong, and Macao land use land cover classification map (2010-2017)

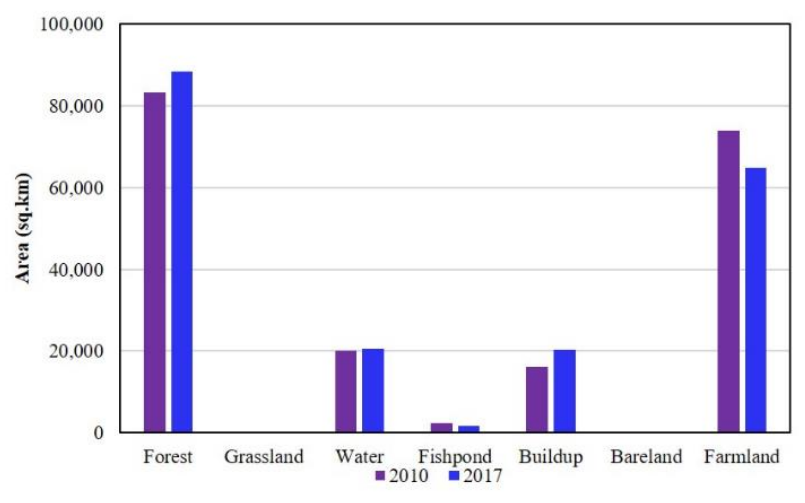

Figure 3. Land use land cover trend in Guangdong, Hong, and Macao from 2010 to 2017.

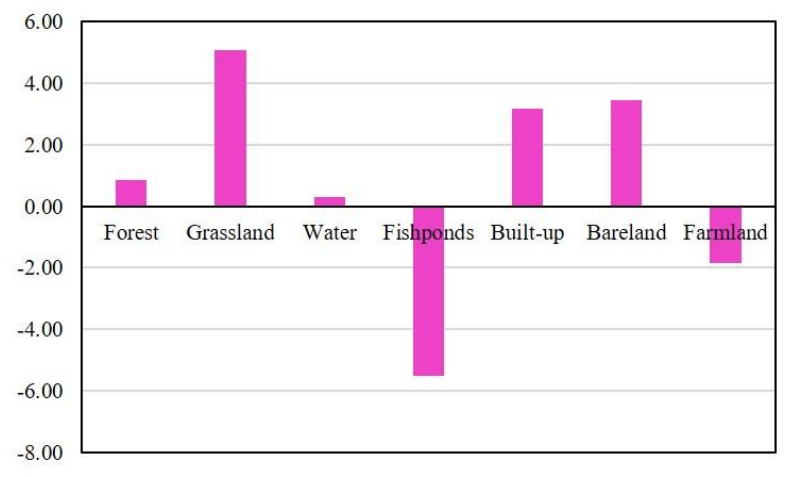

Figure 4. Annual rate of change (2010-2017)

With the increase in built-up area, the gross domestic product increases from 46,036.25 (100 million yuan) in 2010 to $79,512.05$ (100 million yuan) in 2017 reflecting the human activities and development and corresponding reduction in farmland. The total investment in fixed assets of study area has increased from 16,113.19 (100 million Yuan) to 33,008.86 (100 million Yuan) during the period of study. This significant increase in gross domestic product and fixed assets is the result of increase in (1) secondary and tertiary industry, (2) monthly income, (3) demand of luxurious and comfortable life, and (4) convenient transportation. Consequently, the total population increased from 8,521.55 ( 10,000 persons) in 2010 to $9,164.90$ (10,000 persons) in 2017. There is a significant linear relationship with a coefficient of determination $\mathrm{R}^{2}=0.97$ between GDP and population (Figure 5). Thus, with the increase in socioeconomic determinants built-up increases and farmland decreased.

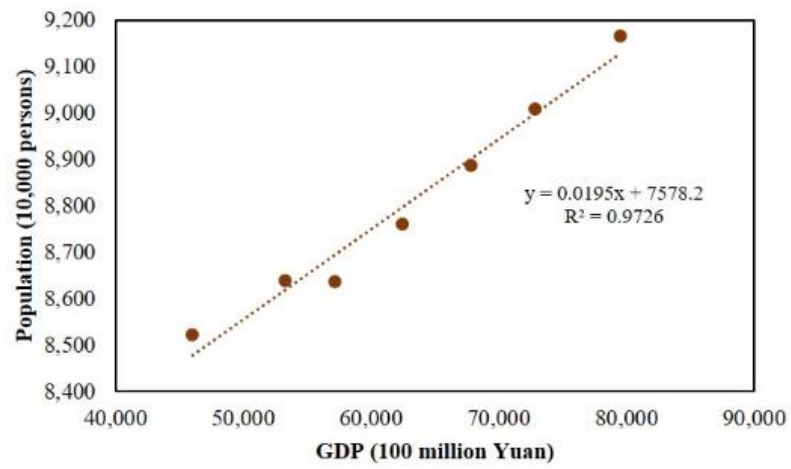

Figure 5. The correlation between gross domestic product (GDP) and population (2010-2017) 


\section{CONCLUSION}

This study has examine the LULC patterns and the relationship between land use land cover changes, urbanization, and socioeconomic factors. The results shows that from 2010 to 2017 the Guangdong, Hong Kong, and Macao has undergone a significant land use land cover changes mainly dominated in built-up land, farmland, and forest. During the studied period, built-up area and forest cover has increased from $8.26 \%$ to $10.31 \%$ and $42.38 \%$ to $45.02 \%$, respectively. On the other hand, the farmland decrease from $37.64 \%$ in 2010 to $33.07 \%$ in 2017 . The main reasons for land use changes were the socioeconomic development, road networks, cheap land rate, job opportunities, foreign direct investment, and industrialization. Furthermore, the marked increase in GDP and total investment in fixed assets have led to the expansion of cities on a large extent. All such changes have caused significant change in the Guangdong, Hong Kong, and Macao land cover. The findings of this paper will help the policy decision makers for inferring the different land use information and analyzing the relationship between land use change and socioeconomic drivers.

\section{ACKNOWLEDGMENTS}

Authors would like to thanks NASA Earth System for Landsat data, National Oceanic and Atmospheric for Administration (NOAA) and China, Hong Kong, and Macao Statistical press for providing Guangdong, Hong Kong, and Macao Statistical Year Book from 1986 to 2017.

\section{REFERENCES}

Abbas, S., Nichol, J. E., \& Wong, M. S. (2018). Objectbased, multi-sensor habitat mapping of successional age classes for effective management of a 70-year secondary forest succession. Land Use Policy, (April), 1-10. https://doi.org/10.1016/j.landusepol.2018.04.035

Araya, Y. H., \& Cabral, P. (2010). Analysis and Modeling of Urban Land Cover Change in Setúbal and Sesimbra, Portugal. Remote Sensing, 2(6), 1549 1563. https://doi.org/10.3390/rs2061549

Bahari, N. I. S., Ahmad, A., \& Aboobaider, B. M. (2014). Application of support vector machine for classification of multispectral data. IOP Conference Series: Earth and Environmental Science, 20(1). https://doi.org/10.1088/1755-1315/20/1/012038

Candade, N., \& Dixon, D. B. (2004). Multispectral Classification of Landsat Images: a Comparison of Support Vector Machine and Neural Network Classifiers. In ASPRS Annual Conference Proceeding (p. 12).

Dou, P., \& Chen, Y. (2017). Dynamic monitoring of landuse/land-cover change and urban expansion in Shenzhen using Landsat imagery from 1988 to 2015. International Journal of Remote Sensing, 38(19), 5388-5407. https://doi.org/10.1080/01431161.2017.1339926

Du, S., Shi, P., \& Van Rompaey, A. (2014). The Relationship between Urban Sprawl and Farmland Displacement in the Pearl River Delta, China. Land,
3(1), 34-51. https://doi.org/10.3390/land3010034

Fan, F., Weng, Q., \& Wang, Y. (2007). Land Use and Land Cover Change in Guangzhou, China, from 1998 to 2003, Based on Landsat TM /ETM+ Imagery. Sensors, 7(7), 1323-1342. https://doi.org/10.3390/s7071323

Gidudu, A., Hulley, G., \& Marwala, T. (2007). Classification of images using Support Vector Machines. arXiv: 0709.3967v1, 1-6.

Hasan, S., Shi, W., Zhu, X., \& Abbas, S. (2019). Monitoring of Land Use/Land Cover and Socioeconomic Changes in South China over the Last Three Decades Using Landsat and Nighttime Light Data. Remote Sensing, 11(14), 1658. https://doi.org/10.3390/rs11141658

Jiang, C., \& Wu, Z. (2015). Impacts of urbanization on net primary productivity in the Pearl River Delta, China. International Journal of Plant Production, 9(4), 581-598.

Li, C., Kuang, Y., Huang, N., \& Zhang, C. (2013). The long-term relationship between population growth and vegetation cover: An empirical analysis based on the panel data of 21 cities in Guangdong province, China. International Journal of Environmental Research and Public Health, 10(2), 660-677. https://doi.org/10.3390/ijerph10020660

Lillesand, T. ., Kiefer, R. W., \& Chipman, J. W. (2008). Remote sensing and image interpretation (6th ed.). John Wiley \& Sons, Hoboken, NJ.

Liping, C., Yujun, S., \& Saeed, S. (2018). Monitoring and predicting land use and land cover changes using remote sensing and GIS techniques-A case study of a hilly area, Jiangle, China. PLOS ONE, 13(7). https://doi.org/10.1371/journal.pone.0200493

Mooney, H. A., Duraiappah, A., \& Larigauderie, A. (2013). Evolution of natural and social science interactions in global change research programs. Proceedings of the National Academy of Sciences, 110 (Supplement_1), 3665-3672. https://doi.org/10.1073/pnas.1107484110

Mountrakis, G., Im, J., \& Ogole, C. (2011). Support vector machines in remote sensing: A review. ISPRS Journal of Photogrammetry and Remote Sensing, 66(3), 247-259. https://doi.org/10.1016/j.isprsjprs.2010.11.001

Pontius, R. G., Shusas, E., \& McEachern, M. (2004). Detecting important categorical land changes while accounting for persistence. Agriculture, Ecosystems \& Environment, 101(2-3), 251-268. https://doi.org/10.1016/j.agee.2003.09.008

Rimal, B., Zhang, L., Keshtkar, H., Haack, B., Rijal, S., \& Zhang, P. (2018). Land Use/Land Cover Dynamics and Modeling of Urban Land Expansion by the Integration of Cellular Automata and Markov Chain. ISPRS International Journal of Geo-Information, 7(4), 154. https://doi.org/10.3390/ijgi7040154

Salih, A. A. M., Ganawa, E.-T., \& Elmahl, A. A. (2017). Spectral mixture analysis (SMA) and change vector analysis (CVA) methods for monitoring and mapping land degradation/desertification in arid and semiarid areas (Sudan), using Landsat imagery. The Egyptian Journal of Remote Sensing and Space 
Science, 20, S21-S29.

https://doi.org/10.1016/j.ejrs.2016.12.008

Shobairi, S. O., \& Li, M. (2016). Dynamic Modelling of VFC from 2000 to 2010 Using NDVI and

DMSP/OLS Time Series: A Study in Guangdong

Province, China. Journal of Geographic Information System, 8(2), 205-223.

https://doi.org/10.4236/jgis.2016.82019

USGS Earth Explorer. (n.d.). Retrieved February 28, 2018 , from https://earthexplorer.usgs.gov/

Ustuner, M., Sanli, F. B., \& Dixon, B. (2015). Application of support vector machines for landuse classification using high-resolution rapideye images: A sensitivity analysis. European Journal of Remote Sensing, 48, 403-422. https://doi.org/10.5721/EuJRS20154823

Wenhua, L. (2004). Degradation and restoration of forest ecosystems in China. Forest Ecology and Management, 201(1), 33-41. https://doi.org/10.1016/j.foreco.2004.06.010

Wu, K., Ye, X., Qi, Z., \& Zhang, H. (2013). Impacts of land use/land cover change and socioeconomic development on regional ecosystem services: The case of fast-growing Hangzhou metropolitan area, China. Cities, 31, 276-284. https://doi.org/10.1016/j.cities.2012.08.003

Xiaowei, X., Xiangxin, C., \& Jianfu, Y. (2017). Guangdong Statistics Yearbook 2017. China Statistics Press.

Zhu, Z., \& Woodcock, C. E. (2014). Continuous change detection and classification of land cover using all available Landsat data. Remote Sensing of

Environment, 144, 152-171.

https://doi.org/10.1016/j.rse.2014.01.011 